\title{
Определение теафлавинов в черных чаях разных стран методом ВЭЖХ с амперометрическим детектором
}

\author{
(С)2020 Яшин А.Я. \\ Компания «Интерлаб», Москва \\ Поступила в редакцию 16.01.2020 г.
}

DOI: $10.17308 /$ sorpchrom.2020.20/2770

В статье были получены сравнительные данные по содержанию теафлавинов в черных чаях разных стран - основных производителей этого напитка: Индия, Шри-Ланка, Китай и Кения. Эти определения были выполнены методом высокоэффективной жидкостной хроматографии (ВЭЖХ) с амперометрическим детектированием. Цель этих анализов - это оценка качества, подлинности и географического происхождения черного чая. Теафлавины - одни из биологически активных полифенолов-антиоксидантов черного чая. По антиоксидантной активности они не уступают антиоксидантной активности катехинам зеленого чая. Поэтому теафлавины, как и катехины защищают человека от опасных заболеваний, в том числе от сердечно-сосудистых, онкологических, нейродегенеративных и других. Черный чай - наиболее употребляемый напиток в мире после воды, $80 \%$ населения земного шара регулярно употребляют черный чай. Во многих странах черный чай - один из основных источников антиоксидантов в диете человека. В обзоре приведены методы хроматографии, применяемые для определения теафлавинов в указанных чаях. В качестве детектирующих систем применялись наиболее известные детекторы: масс-спектрометрические и диодноматричные. В статье приведены сведения по антиоксидантной активности исследуемых черных чаев, измеренных амперометрическим методом. Эти измерения наиболее точные, т.к. этот детектор регистрирует только антиоксиданты, поэтому сумма площадей всех пиков на хроматограмме может быть мерой антиоксидантной активности. Содержание теафлавинов в черных чаях разных стран, оцененное по площадям пиков находятся в таком порядке: теафлавин-3-галлат<теафлавин-3,3'-дигаллат<теафлавин<теафлавин-3’-галлат. Наибольшей антиоксидантной активностью обладают черные чаи из Кении, Индии и Шри-Ланки. Неудивительно, что чай из Кении занимает высокое место, т.к. там он растет в тропиках при идеальных условиях по температуре, влажности и качеству вулканических почв. Кения по экспорту черного чая вышла на первое место в мире. Приведенные в статье новые сведения будут полезны потребителям черного чая. Нужно отметить, что по последним данным антиоксиданты черного чая подавляют вредное действие свободных радикалов при окислительном стрессе. Кроме того, показано, что черный чай благотворно влияет на микробиоту кишечника человека, а чем лучше состояние микробиоты, тем здоровее человек.

Ключевые слова: черный чай, хроматография, амперометрический детектор, антиоксидантная активность, теафлавины, катехины, полифенолы-антиоксиданты.

\section{Введение}

Производят несколько видов чая, основными из которых являются черный, зеленый и оолонг (или улун). Зеленый чай - это высушенные листья чая, черный чай полностью ферментированный, чай оолонг ферментирован на $50 \%$. В зеленом чае основные полифенолы-антиоксиданты-катехины (6-8 видов), при ферментации чая катехины полимеризуются в теафлавины и теарубигины [1]. На рис.1 приведены структурные формулы теафлавинов. В таблице 1 приведены предшественники те- 
афлавинов и их содержание в черном чае.

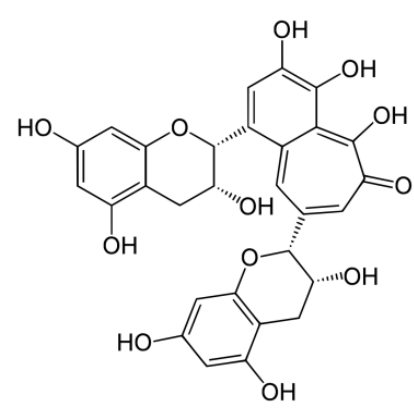

1<smiles>Cc1cc(O)c2c(c1)OC(C1Oc3cc(O)cc(O)c3CC1OC(=O)c1cc(O)c(O)c(O)c1)C(O)C2</smiles>

3

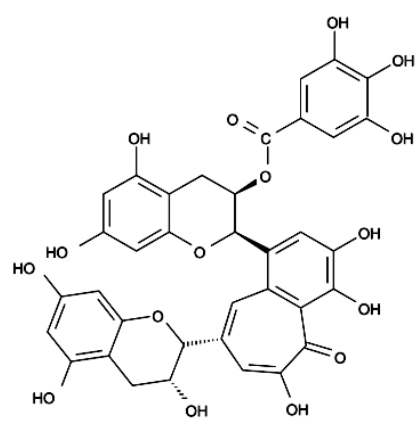<smiles>[3H]</smiles>

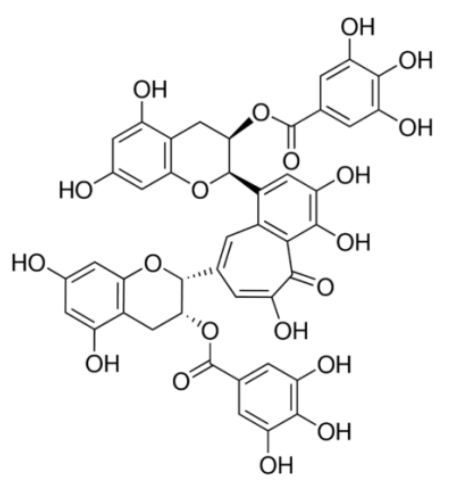

4

Рис. 1. Структурные формулы теафлавинов. 1 - теафлавин; 2 - теафлавин-3галлат; 3 - теафлавин -3`-галлат; теафлавин-3,3`-дигаллат

Таблица 1. Теафлавины в черном чае (предшественники и содержание в черном чае) [1]

\begin{tabular}{|c|c|c|c|}
\hline$№$ & Предшественники & Теафлавины & Содержание в \% от сухого веса \\
\hline 1 & ЭК+ЭГК & теафлавин & $0.2-0.3$ \\
\hline 2 & ЭК+ЭГКГ & теафлавин-3-галлат & $1.0-1.5$ \\
\hline 3 & ЭКГ+ЭГК & теафлавин-3'-галлат & $1.0-1.5$ \\
\hline 4 & ЭКГ+ЭГКГ & теафлавин-3,3'-дигаллат & $0.6-1.2$ \\
\hline
\end{tabular}

В настоящее время показано, что по антиоксидантной активности теафлавины не уступают катехинам зеленого чая [2], поэтому они, также как и катехины, обладают оздоровительным действием на человека, в частности, противовоспалительным [3], антимикробным [3], антиканцерогенным [1] и защищают человека от сердечнососудистых заболеваний [4].

Теафлавины определяют в черных чаях разными методами хроматографии (таблица 2). Цель анализа - оценка качества [22], идентичности и географического происхождения $[22,23]$. Были исследованы методом ВЭЖХ состав полифенолов в чае из Конго [9], Турции [16], стран Центральной и Южной Африки [22], из разных областей Индии [23]. Содержание теафлавинов, а также других соединений, было определено в 70 чаях, потребляемых в США [24]. Теафлавины методом ВЭЖХ были определены в биологических жидкостях человека после употребления черного чая [14]. Отдельно измерялась антиоксидантная активность только черного чая [25], а также одновременно антиоксидантная активность черного, зеленого, белого, желтого и оолонг чая [26].

Общие вопросы влияния полифенолов черного чая на здоровье человека рассмотрены в книге [27] и обзорах $[28,29]$. Важно отметить, что черный чай благотворно влияет на микробиоту кишечника человека [4], а чем лучше состояние мик- 
робиоты, тем лучше здоровье человека. Черный чай в некоторых странах является основным источником поступления полифенолов-антиоксидантов в организм человека [30], среди людей регулярно пьющих черный чай. Большинство населения земного шара пьют черный чай (75-80\%). Потребление черного чая улучшает микроциркуляцию крови [31], теафлавины черного чая снижают мутагенность и канцерогенность гетероциклических аминов [32], полифенолы черного чая защищают от окисления молекул ДНК при сильном окислительном стрессе [33]. Теафлавин-3,3 дигаллат по антиканцерогенности против рака не уступает эпигаллокатехин галлату зеленого чая [34,35].

Таблица 2. Хроматографические методы анализа теафлавинов в черном чае

\begin{tabular}{|c|c|c|}
\hline & & Ссылки \\
\hline 1 & $\begin{array}{c}\text { Газо - жидкостная хроматография (ГЖХ). Теафлавины дериватизиру- } \\
\text { ются в триметилсилильные эфиры }\end{array}$ & 5 \\
\hline 2 & Высокоэффективная жидкостная хроматография (ВЭЖХ) & $6-9$ \\
\hline 3 & ВЭЖХ на монолитной колонке & 10 \\
\hline 4 & ВЭЖХ на колонке С12 & 11 \\
\hline 5 & ВЭЖХ с твердофазной экстракцией & 12 \\
\hline 6 & ВЭЖХ с диодноматричным детектором (ДМД) & 11,13 \\
\hline 7 & ВЭЖХ с масс-спектрометрическим детектором (МС) & 14 \\
\hline 8 & ВЭЖХ с МС/МС детектором & 15 \\
\hline 9 & ВЭЖХ с ДМД и МС/МС детекторами & 16 \\
\hline 10 & Полупрепаративная ВЭЖХ & 17 \\
\hline 11 & Ультра ВЭЖХ & 18,19 \\
\hline 12 & Двумерная ВЭЖХ & 19 \\
\hline 13 & Высокоскоростная противоточная хроматография & 20 \\
\hline 14 & Капиллярный электрофорез & 21 \\
\hline
\end{tabular}

\section{Эксперимент}

Измерения выполнены на жидкостном хроматографе «МаэстроВЭЖХ» с амперометрическим детектором в градиентном режиме. Для разделения использовалась колонка размером 4.6 на 250 мм, заполненная сорбентом Кромасил С18 с размером частиц 5 мкм. Скорость элюента $1 \mathrm{~cm}^{3} /$ мин. Элюент - А - Ацетонитрил, содержащий $1 \mathrm{~cm}^{3} \mathrm{H}_{3} \mathrm{PO}_{4}$ (конц), В - бидистиллированная вода, содержащая $1 \mathrm{~cm}^{3}$ $\mathrm{H}_{3} \mathrm{PO}_{4}$ (конц). Условия для градиентного элюирования приведены в таблице 3. Для определения времени удерживания теафлавинов при данных условиях использовали их чистые вещества фирмы Fluka. Навеску чая массой 1 г заваривали 50 cм$^{3}$ количеством горячей воды температурой 90-100 град. Время заварки - 10 минут. Чай фильтровался через 0.45 мкм фильтр-насадку и вводился в хроматограф.

Таблица 3. Условия для градиентного элюирования

\begin{tabular}{|c|c|c|}
\hline Время, мин & $\mathrm{A}, \%$ & $\mathrm{~B}, \%$ \\
\hline 0 & 10 & 90 \\
\hline 3 & 10 & 90 \\
\hline 15 & 30 & 70 \\
\hline 23 & 25 & 75 \\
\hline 24 & 10 & 90 \\
\hline 31 & 10 & 90 \\
\hline
\end{tabular}

Образцы чая были получены непосредственно у производителей чая на специализированных выставках. 


\section{Обсуждение результатов}

На рис 2 приведена хроматограмма черного чая Ruhuna из Шри-Ланки, а на рис. 3 хроматограммы всех проанализированных черных чаев из разных стран. В таблице 4 указаны площади пиков отдельных теафлавинов, которые пропорциональны их количествам в черном чае. В таблице 5 приведены значения суммы площадей всех пиков на хроматограмме и суммы площадей всех теафлавинов, а также процентное соотношение теафлавинов.

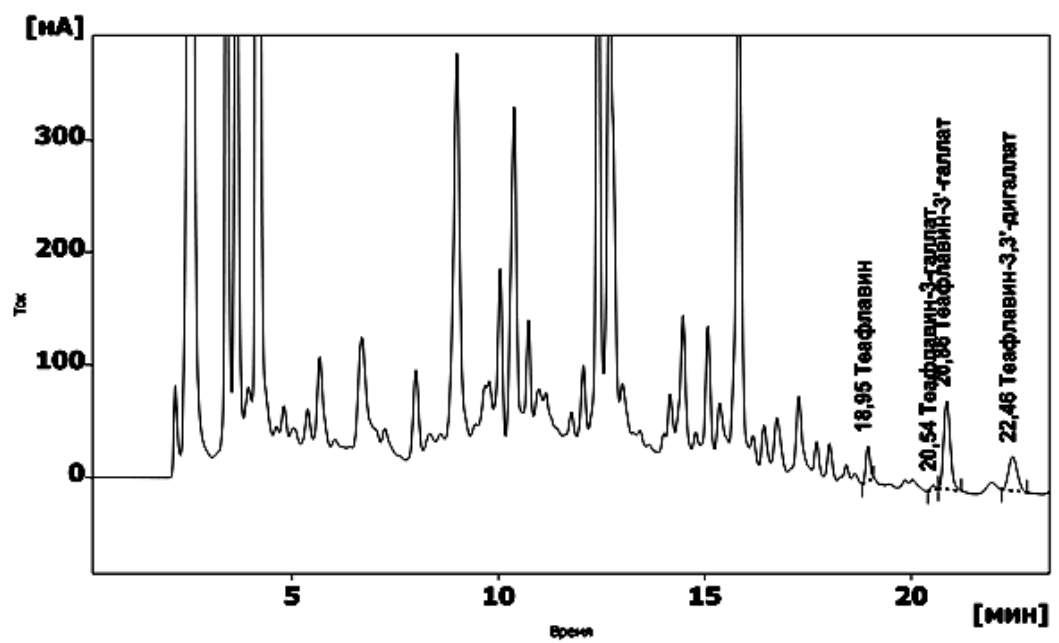

Рис. 2. Хроматограмма черного чая Ruhuna из Шри-Ланки

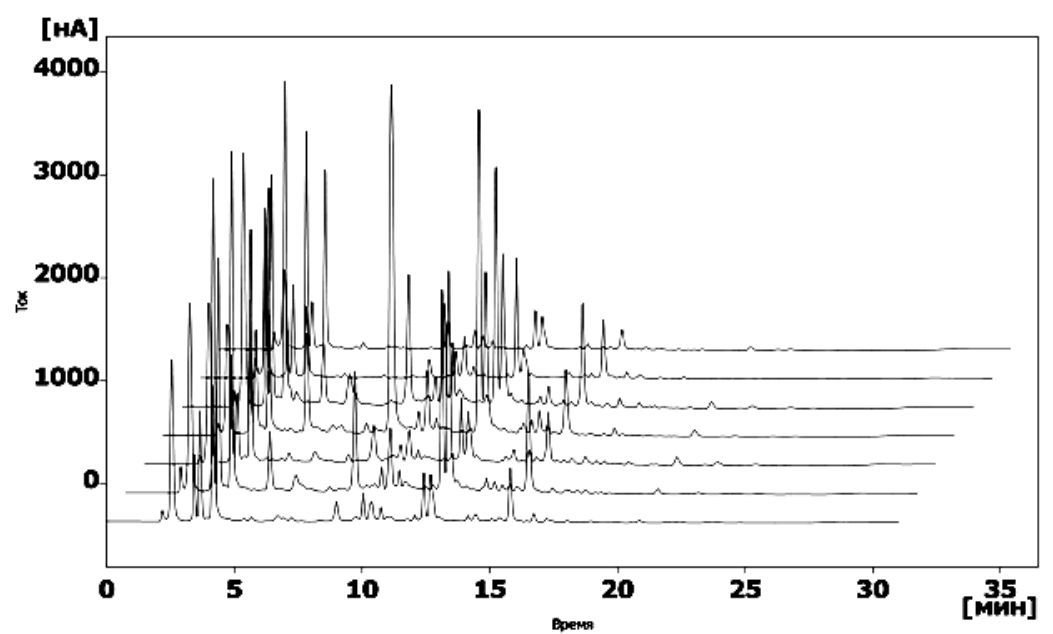

Рис. 3. Хроматограммы исследованных черных чаев из разных стран.

1 - байховый мелкий Impra купаж Цейлонский, 2 - чай черный китайский крупнолистовой Дянь Хун, 3 - черный чай Кения 1193 OPA, 4 - черный чай Шри Ланка Nuwara Eliya, 5 - черный чай Шри Ланка Ruhuna, 6 - черный чай Шри Ланка Uva, 7 - черный чай Шри Ланка Sabaragamuwa.

Амперометрический детектор регистрирует только те соединения, которые обладают антиоксидантной активностью, поэтому сумма площадей всех пиков на хроматограмме может служить мерой антиоксидантной активности измеренных черных чаев, а процентное отношение теафлавинов указывает на вклад их в общую антиоксидантную активность. В первую пятерку чаев с наибольшей антиоксидантной активностью входят два элитных чая Шри-Ланки, два известных чая Индии и один чай из Кении. 
Таблица 4. Площади пиков отдельных теафлавинов, которые пропорциональны их количествам в черном чае

\begin{tabular}{|c|c|c|c|c|c|}
\hline & Теафлавин & $\begin{array}{c}\text { Теафлавин- } \\
\text { 3-моногаллат }\end{array}$ & $\begin{array}{c}\text { Теафлавин- } \\
\text { 3'-галлат }\end{array}$ & $\begin{array}{c}\text { Tеафлавин- } \\
\text { 3,3'-дигаллат }\end{array}$ & Сумма \\
\hline & $\begin{array}{c}\text { Площадь } \\
\text { [нА.сек] }\end{array}$ & $\begin{array}{c}\text { Площадь } \\
\text { [нА.сек] }\end{array}$ & $\begin{array}{c}\text { Площадь } \\
\text { [нА.сек] }\end{array}$ & $\begin{array}{c}\text { Площадь } \\
\text { [нА.сек] }\end{array}$ & $\begin{array}{c}\text { Площадь } \\
\text { [нА.сек] }\end{array}$ \\
\hline $\begin{array}{c}\text { черный чай } \\
\text { Шри Ланка } \\
\text { Ruhuna }\end{array}$ & 216.837 & 30.187 & 873.357 & 449.677 & 1570.1 \\
\hline $\begin{array}{c}\text { черный чай } \\
\text { Кения } 1193 \\
\text { OРА }\end{array}$ & 103.606 & 13.867 & 754.252 & 353.873 & 1225.6 \\
\hline $\begin{array}{c}\text { чай черный } \\
\text { Pure Assam } \\
\text { Kho-Cha } \\
\text { Teas } \\
\end{array}$ & 97.872 & 35.985 & 435.783 & 364.02 & 933.7 \\
\hline $\begin{array}{c}\text { черный чай } \\
\text { Шри Ланка } \\
\text { Nuwara Eliya }\end{array}$ & 15.458 & - & 762.418 & 88.804 & 866.7 \\
\hline $\begin{array}{l}\text { чай черный } \\
\text { Pure Nilgiri } \\
\text { Golden Tips }\end{array}$ & 55.107 & 3.834 & 562.802 & 242.317 & 864.1 \\
\hline $\begin{array}{c}\text { черный чай } \\
\text { Шри Ланка } \\
\text { Uva }\end{array}$ & 38.29 & - & 567.559 & 216.623 & 822.5 \\
\hline $\begin{array}{c}\text { черный чай } \\
\text { Шри Ланка } \\
\text { Sabara- } \\
\text { gamuwa }\end{array}$ & 83.787 & 33.43 & 241.56 & 163.704 & 522.5 \\
\hline $\begin{array}{c}\text { байховый } \\
\text { мелкий } \\
\text { Impra купаж } \\
\text { Цейлонский } \\
\end{array}$ & 52.061 & 10.173 & 332.836 & 117.941 & 513.0 \\
\hline $\begin{array}{l}\text { чай черный } \\
\text { Lipton } \\
\text { Darjeeling }\end{array}$ & 35.553 & - & 250.495 & 97.087 & 383.1 \\
\hline $\begin{array}{c}\text { чай черный } \\
\text { китайский } \\
\text { крупноли- } \\
\text { стовой Дянь } \\
\text { Хун }\end{array}$ & 168.327 & 24.371 & 74.639 & 41.564 & 308.9 \\
\hline $\begin{array}{c}\text { чай черный } \\
\text { китайский } \\
\text { Росток дра- } \\
\text { кона } \\
\end{array}$ & 80.628 & 32.318 & 26.842 & 32.51 & 172.3 \\
\hline
\end{tabular}

Приведенные чаи из Индии и Шри-Ланки закономерно занимают верхние строчки по антиоксидантной активности, может вызвать вопрос качество чая из Кении. Нужно напомнить, что Кения в последние годы занимает первое место по экспорту чая, опережая Шри-Ланку. Чай в Кении выращивают около тропиков в идеальных условиях по температуре и влажности. Технология производства стала современной, поэтому спрос на чай из Кении возрос на мировом рынке. Содержание разных теафлавинов в черных чаях разных стран, если оценивать по площадям пиков 
находятся, в основном, в таком порядке: теафлавин-3-галлат<теафлавин-3,3`дигаллат<теафлавин<теафлавин-3’-галлат.

Таблица 5. Суммы площадей всех пиков на хроматограмме и суммы площадей всех теафлавинов, а также процентное соотношение теафлавинов

\begin{tabular}{|c|c|c|c|}
\hline Название & $\begin{array}{l}\text { Сумма площадей } \\
\text { всех пиков, нА с }\end{array}$ & $\begin{array}{c}\text { Сумма площадей пиков } \\
\text { теафлавинов, нА с }\end{array}$ & $\begin{array}{l}\text { \% содержа- } \\
\text { ния теафла- } \\
\text { винов }\end{array}$ \\
\hline $\begin{array}{l}\text { черный чай кения } 1193 \\
\text { OРА }\end{array}$ & 144184.33 & 1225.60 & 0.85 \\
\hline $\begin{array}{c}\text { черный чай Шри Ланка } \\
\text { Nuwara Eliya }\end{array}$ & 139918.36 & 866.68 & 0.62 \\
\hline $\begin{array}{c}\text { черный чай Шри Ланка } \\
\text { Uva пакетик }\end{array}$ & 132343.61 & 822.47 & 0.62 \\
\hline $\begin{array}{l}\text { чай черный Lipton } \\
\text { Darjeeling }\end{array}$ & 111713.57 & 383.14 & 0.34 \\
\hline $\begin{array}{c}\text { чай черный Pure Nilgiri } \\
\text { Golden Tips } \\
\end{array}$ & 100583.18 & 864.06 & 0.86 \\
\hline $\begin{array}{c}\text { чай черный Pure Assam } \\
\text { Kho-Cha Teas }\end{array}$ & 87156.35 & 933.66 & 1.07 \\
\hline $\begin{array}{c}\text { черный чай Шри Ланка } \\
\text { Sabaragamuwa }\end{array}$ & 71797.48 & 522.48 & 0.73 \\
\hline $\begin{array}{l}\text { черный чай Шри Ланка } \\
\text { Ruhuna } \\
\end{array}$ & 69331.69 & 1570.06 & 2.26 \\
\hline $\begin{array}{c}\text { чай черный китайский } \\
\text { Дянь Хун } \\
\end{array}$ & 63133.19 & 308.90 & 0.49 \\
\hline $\begin{array}{c}\text { чай черный китайский Ро- } \\
\text { сток дракона }\end{array}$ & 42953.26 & 172.30 & 0.40 \\
\hline $\begin{array}{c}\text { байховый мелкий Impra } \\
\text { купаж Цейлонский }\end{array}$ & 38399.83 & 513.01 & 1.34 \\
\hline
\end{tabular}

\title{
Заключение
}

В кратком обзоре впервые проведено сравнение известных черных чаев из разных стран по содержанию теафлавинов и по суммарной антиоксидантной активности. Эти сведения будут полезны потребителям черного чая. Как показано ранее потребление черного чая защищает человека от самых опасных болезней, а также нейтрализует вредное действие свободных радикалов при окислительном стрессе предшественнике многих болезней. Важно еще раз напомнить, что черный чай благотворно влияет на микробиоту кишечника человека.

\section{Determination theaflavins in black teas of the different countries by HPLC method with amperometric detector}

\author{
(C) 2020 Yashin A.Ya. \\ Company "Interlab", Moscow
}

The article compares the results of the analysis of theaflavin concentrations in black teas produced by different countries, i.e. its main manufacturers: India, Sri Lanka, China, and Kenya. The results were obtained by means of high performance liquid chromatography (HPLC) with amperometric detection. The aim of such analysis was to assess the quality and to identify the country of origin of black teas. Theaflavins rep- 
resent biologically active polyphenols-antioxidants of black tea. They compete with the catechins of green teas in terms of antioxidant activity. Hence, both theaflavins and catechins protect humans against many dangerous diseases, including cardio-vascular, oncology, neurodegenerative diseases, etc. Black tea is the most common drink after water. $80 \%$ of the global population regularly drink black tea. In many countries, black tea is the main source of antioxidants in the human diet. The overview presents chromatography methods which can be used to determine theaflavins in tea. The study used the most well-known detectors: mass spectrometry and diode-array. The article presents the antioxidant activity data for the studied black teas obtained by means of the amperometric method. Such measurements are the most precise as the detector can only record antioxidants, therefore, the total area of all chromatographic peaks can be a measure of antioxidant activity. The concentrations of theaflavins in black teas produced by different countries assessed by the peak area are presented in the following order: teaflavin-3-gallate $<$ teaflavin-3,3 ${ }^{`}$-digallat $<$ teaflavin $<$ teaflavin- $3^{`}$ gallate. The most antioxidant active are black teas from Kenya, India, and Sri-Lanka. It is not surprising that Kenyan tea takes such a high position as it grows in tropics in perfect conditions in terms of temperature, humidity, and the quality of volcanic soil. Kenya is the leading global exporter of black tea. The new data presented in the article will be beneficial for black tea consumers. It should be noted that according to the latest data black antioxidants mitigate the harmful effects of free radicals associated with oxidative stress. Moreover, it has been proved that black tea has a positive effect on intestinal microbiota and the better is the condition of intestinal microbiota the healthier is the person.

Keywords: black tea, chromatography, amperometric detector, antioxidant activity, theaflavins, catechins, polyphenols-antioxidants

\section{Список литературы/References}

1. Singh B.N., Rowat A.K.S., Bhagat R.M., Singh R.R., Crit. Rev. Food Sci. Nutr., 2017, Vol. 57, pp.1394-1410.

2. Leung L.K., Su K., Chen R. et al., J. Nutr., 2001, Vol. 131, pp.2248-2251.

3. Zu M., Yang F., Zhou W.L. et al., Antiviral Research, 2012, Vol. 94, pp. 217-224.

4. Van Duyhoven J., Vaughan E.E., Van Dorsten F. et al., Amer. J. Clin. Nutr., 2013,. Vol. 98, pp. 1631S-1641S.

5. Collier P.D., Mallows R., J. Chromat. A, 1997, Vol. 57, pp.19-27.

6. Robertson A., Bendall D.S., Phytochemistry, 1983, Vol. 22, pp. 883-887.

7. Wang Y., Yang X., Li K. et al., Int. J. Food Sci. Techn., 2010, Vol. 45, pp. 1263-1269.

8. Li D.X., Wan X.C., Liu L.H. et al., J. Tea Sci., 2004. V.24. p.124-128.

9. Honglin L.L., Tong H.R., Food Sci., 2016 , Vol. 37, pp. 97-101.

10.Zang J., Cui H., Jiang H. et al., Cztch. J. Food Sci., 2019, Vol. 37, pp.112-119.

11.Rana A., Singh H.P., J. Liq. Chromat. Relat. Techn., 2012, Vol. 35, pp. 2272-2279.

12. Nishimura M., Ishiyana K., Watanoba A. et al., J. Agric. Food Chem., 2007, Vol. 55, pp.7252-7257.

13.Neilson P.A., Green J.R., Wood V.K., Ferruzzi G.M., J. Chromat., 2006, Vol. 1132, pp. 132-140.

14.Mulder T.P., Van Platerink C.J. Wijnand P.J. et al., J. Chromat. B, 2001, Vol. 760, pp. 271-279.
15.Tao W.Q., Zhou Z.G., Zhao B., Wei T.Y., $J$ Pharmac. Biomed. Analysis, 2016, Vol. 131, pp. 140-145.

16.Kelebek H., Food Chem., 2016, Vol. 204, pp. 227-238.

17.Xu Y., Jin Y., Wu Y.Y., Tu Y.Y., J. Liq. Chromat. Rel. Tech., 2010, Vol. 33, pp. 17911801.

18.Pan H.-B., Zang D., Li B. et al., J. Chromat. Sci., 2017, Vol. 55, pp. 495-496.

19.Scoparo C.T., de Souza L.M., Dartira N. et al., J. Chromat. A, 2012, Vol. 1222, pp. 29-37.

20.Wang K.B., Liu Z.H., Huang J.A. et al., J. Chromat. B, 2008, Vol. 867, pp. 282-286.

21.Lee B.L., Ong C.N., J. Chromat. A, 2000, Vol. 881, pp. 439-447.

22. Wright L.P., Mphangwe N.I.K. et al., J. Sci Food Agric., 2002, Vol. 82, pp. 517-525.

23.Borse B.B., Rao L.J.M. et al., Food Chem., 2002, Vol. 79, pp. 419-424.

24.Friedman M., Kim S.Y., Lee S.J. et al., J.Food Sci., 2005, Vol. 70, pp. 550-559.

25.Luczaj W., Skrzydlewska E., Prev. Med., 2005, Vol. 40, pp. 910-918.

26.Zhao C.-N., Tang G.-Y., Cao S-Y. et al., Antioxidants, 2019, Vol. 8, pp. 215.

27.Preedy V.R. (Ed). Tea in health and disease prevention. Sun Diego, Academic Press. 2012. $1555 \mathrm{p}$.

28.Butt M.S., Imran A., Sharif M.K. et al., Crit. Rev. Food Sci. Nutr., 2014, Vol. 54, pp. 1002-1011.

29.Sharma V, Rao LJ., Crit. Rev Food Sci 
Nutr., 2009, 49(5), pp. 379-404.

30. Rechner A.R., Wagnes E., Van Buren L. et al., Free Radical Res., 2002, Vol. 36, pp. 11271135.

31.Fuchs D, de Graaf $Y$, van Kerckhoven R, Draijer R., Nutrients, 2014, 6(12), pp. 57725785.

32.Stavric B, Matula TI, Klassen R, Downie RH., Food Chem Toxicol., 1996, Vol. 34(6), pp.

Яшин Александр Яковлевич - к.х.н., зам. руководителя отдела исследований и разработок, компания «Интерлаб», Москва
515-523.

33.Ježovičová M, Koňariková K, Duračková Z, Keresteš J. et al., Mol Med Rep., 2016, Vol. 13(2), pp. 1839-44.

34. Gao Y, Rankin GO, Tu Y, Chen YC., Int $J$ Oncol., 2016, Vol. 48(1), pp. 281-292.

35. Kimutai, Kanyiri S., Thomas W., Kinyanjui Karori, Muthiani S. et al., Food and $\mathrm{Nu}$ trition Sciences, 2016, Vol. 7, pp. 180-191.

Yashin Alexander Ya. - $\mathrm{PhD}$ in Chemistry, Deputy Head of the R\&D Department company "Interlab", Moscow 